\title{
Author Correction: Validation of the Sleep Regularity Index in Older Adults and Associations with Cardiometabolic Risk
}

\author{
Jessica R. Lunsford-Avery, Matthew M. Engelhard, Ann Marie Navar \& Scott H. Kollins
}

Correction to: Scientific Reports https://doi.org/10.1038/s41598-018-32402-5, published online 21 September 2018

The Article contains an error in Equation 3.

$$
\frac{1440}{2 \pi} \arctan 2\left(\sum_{j=1}^{M} \sum_{i=1}^{M} s_{i, j} \sin \frac{2 \pi t_{i}}{1440}+\sum_{j=1}^{M} \sum_{i=1}^{M} s_{i, j} \cos \frac{2 \pi t_{i}}{1440}\right)
$$

should read:

$$
\frac{1440}{2 \pi} \arctan 2\left(\sum_{j=1}^{M} \sum_{i=1}^{M} s_{i, j} \sin \frac{2 \pi t_{i}}{1440}, \sum_{j=1}^{M} \sum_{i=1}^{M} s_{i, j} \cos \frac{2 \pi t_{i}}{1440}\right)
$$

Additionally, the Article contains a typographical error in the Methods section under subheading 'Calculation of Sleep Regularity Index (SRI) and other sleep indices' where,

"Sleep midpoint, our index of sleep timing, was calculated as a mean of circular quantities (appropriate for time of day) using the following equation (3), where $t_{j}$ denotes time of day in minutes at epoch $j: "$

should read:

"Sleep midpoint, our index of sleep timing, was calculated as a mean of circular quantities (appropriate for time of day) using the following equation (3), where $t_{j}$ denotes time of day in minutes at epoch $j$, $\operatorname{and} \arctan 2(x, y)$ denotes the angle between $(x, y)$ and the positive $x$-axis."

(i) Open Access This article is licensed under a Creative Commons Attribution 4.0 International Cicense, which permits use, sharing, adaptation, distribution and reproduction in any medium or format, as long as you give appropriate credit to the original author(s) and the source, provide a link to the Creative Commons license, and indicate if changes were made. The images or other third party material in this article are included in the article's Creative Commons license, unless indicated otherwise in a credit line to the material. If material is not included in the article's Creative Commons license and your intended use is not permitted by statutory regulation or exceeds the permitted use, you will need to obtain permission directly from the copyright holder. To view a copy of this license, visit http://creativecommons.org/licenses/by/4.0/.

(C) The Author(s) 2020 